\title{
LA LECTURA EN LA OBRA DE ERNESTO SABATO
}

\author{
POR \\ NICASIO URBINA \\ Georgetown University
}

\section{INTRODUCCIÓN}

Un aspecto fascinante de la literatura de Sábato es su preocupación con el fenómeno de la lectura. Hay, a todo lo largo de sus obras, una conciencia plena de ese individuo que, al otro lado del proceso semiótico, hace realidad el texto. El lector que preocupa a Sábato es, por supuesto, el «hombre concreto», el joven que busca algún sentido a su existencia, el pequeño héroe de todos los días. Para Sábato, la literatura es una experiencia vital, una catarsis, y, en consecuencia, la lectura es una forma de experimentar otras realidades y hacerlas vivencias. En Abaddón el exterminador ' (de aquí en adelante $A E E$ ), el personaje Sábato reflexiona sobre el tema: «¿Sentirían otros escritores lo que él experimentaba ante un desconocido que ha leído sus libros? Una mezcla de vergüenza, curiosidad y temor. A veces, como en este momento, era un chico, un estudiante que lleva las insignias de sus tribulaciones y amarguras, y entonces trataba de imaginarse por qué leía sus libros, qué páginas podrían ayudarlo en sus ansiedades y cuáles, por el contrario, sólo servirían para intensificarlas; qué fragmentos marcaría con ferocidad o alegría...» (59). Estas preguntas, dramatizadas en un personaje como Sábato, son prueba fehaciente de que para Sábato la lectura no es una preocupación secundaria, sino el tema central de su obra y su actividad creadora.

El estudio de la relación sujeto-lector ocupa hoy un lugar central en

1 Ernesto Sábato, El túnel (Barcelona: Seix Barral, 1983, 2.a edición en Biblioteca de Bolsillo, 1984); Sobre héroes y tumbas (Barcelona: Seix Barral, 1. ${ }^{a}$ edición definitiva en Biblioteca Breve, 1978); El escritor y sus fantasmas (Buenos Aires: Emecé, 2. impresión en Grandes Ensayistas, 1976); Abbadón el exterminador (Barcelona: Seix Barral, 1. ${ }^{a}$ edición definitiva en Biblioteca Breve, 1978). 
los estudios de crítica literaria y, con el auge de la crítica de la lectura y de la teoría de la recepción estética, se ha puesto especial énfasis en la participación del lector como parte de la «realización» del texto. Como dice Suleiman ${ }^{2}$ : "Today, one rarely picks up a literary journal on either side of the Atlantic without finding articles (and often a whole special issue) devoted to the performance of reading, the role of feelings, the variability of individual response, the confrontation, transaction, or interrogation between texts and readers, the nature and limits of interpretation-questions whose very formulation depends on a new awareness of the audience as an entity indissociable from the notion of artistic text» (3-4).

Sábato, por su parte, aborda con sarcasmo el énfasis que recientemente la crítica ha puesto en la participación del lector; «Como si antes el lector no participara», dice en $A E E$. Pero a pesar de su habitual sarcasmo ante los postulados de la crítica, Sábato depende, en sus obras, de manera fundamental, en la participación del lector. Este trabajo tiene por objeto investigar estas instancias en las tres novelas de Sábato, y demostrar la importancia que el proceso de lectura tiene en la producción de significado.

\section{FUNCIÓN DE LA LECTURA}

La lectura tiene una función gnoseológica; es una forma del conocimiento y al mismo tiempo es su vehículo, su instrumental. Leer es un intento del hombre de conocer mundos distintos y comprenderlos, es el intento de descifrar el universo y entenderlo. No obstante, entender y comprender el mundo encierra en sí una finalidad más íntima y profunda: la necesidad de entenderse a sí mismo.

Una de las preguntas más importantes en el marco teórico contemporáneo es el de la producción de significado en el proceso de la lectura. A este propósito se ha dedicado un sinnúmero de estudios críticos que van desde el trabajo de Ogden \& Richards ${ }^{3}$ hasta los trabajos más recientes en el marco conceptual de la semiótica, como los de Eco ${ }^{4}$, Derri-

${ }^{2}$ Susan R. Suleiman, «Introduction: Varieties of Audience-Oriented Criticism», en The Reader in the Text, Suleiman and I. Crosman, eds. (Princeton: Princeton University Press, 1980), pp. 3-45.

3 C. K. Ogden \& I. A. Richards, The meaning of meaning (London: Routledge and Kegan Paul, 1923).

4 Umberto Eco, Opera aperta (Milano: Valentino Bompiani, 1962); en español: Obra abierta (Barcelona: Ariel, 1979); La struttura assente (Milano, Bompia- 
da ${ }^{5}$, Fish ${ }^{6}$ e Iser ${ }^{7}$, entre otros. Las conclusiones a las que se ha llegado son, en suma, plurales y a menudo contradictorias. Mientras para Hirsch ${ }^{8}$ el significado del texto está sujeto al significado que el autor intentó transmitir a través de la escritura, para críticos como Eco (1979) el significado responde más a las diferentes posibilidades que el lector es capaz de sustentar en el texto. Crosman ${ }^{9} 11$ eva a cabo una evaluación que, si bien no aporta elementos nuevos a la discusión, establece claramente una medida intermedia entre lo que llamamos la «intención autorial» y la «autoridad interpretativa». En respuesta a la primera de estas afirmaciones, Crosman arguye, en el citado artículo, que «the act of understanding a poet's words by placing them in the context of his intentions is only one of a number of possible ways of understanding them» (151). Y más adelante agrega que «the hope for univocality of literary texts appears not only naive but misguided. In order to serve the various needs and desires of various readers, texts ought to have various meanings» (162). Sin embargo, la idea original de Eco (1962), de la «opera aperta», no resulta ser del todo instrumental, ya que, con cierta imaginación, cualquier lector puede documentar su lectura, por disparatada que ésta sea. Por lo tanto, si bien es imprescindible la perspectiva plurívoca del texto, es igualmente fundamental aceptar que el texto contiene en sí un cierto número de posibilidades interpretativas, y que por plurales y variadas que éstas sean, tienen en sí un límite.

Como ha probado Fish (1980), la lectura es fundamentalmente un problema de interpretación. El significado que un lector extrae de un texto está condicionado, en primer lugar, por las posibilidades del texto mismo, por las asociaciones e imágenes que evoca; pero en el proceso de lectura, el sujeto lector aporta una serie de experiencias y valores, un mundo de adquisiciones previas, de expectativas y sentidos del discurso narrativo que se incorporan al texto en el acto de leer y contribuyen al

ni, 1968); La estructura ausente (Barcelona: Lumen, 1974); Lector in fabula (Milano, Bompiani, 1979).

5 Jacques Derrida, De la grammatologie (Paris: Éditions du Minuit, 1967).

6 Stanley E. Fish, Is There a Text in This Class? (Cambridge: Harvard University Press, 1980).

7 Wolfgang Iser, The Implied Reader: Patterns of Communication in Prose Fiction from Bunyan to Beckett (Baltimore: John Hopkins University Press, 1976); "Interaction Between Text and Reader», en The Reader in the Text, ut supra, pp. 106-119.

8 E. D. Hirsch Jr., The Aims of interpretation (Chicago: University of Chicago Press, 1979).

9 Robert Crosman, «Do Readers Make Meaning?», en The Reader in the Text, op. cit., pp. 149-164. 
resultado final, es decir, a la significación del texto. Sábato discute este asunto en $A E E$ a través del personaje Sábato: «Lo que más le asombraba era esa variedad de seres que pueden leer el mismo libro, como si fueran muchos y hasta infinitos libros diferentes: un único texto que no obstante permite innumerables interpretaciones, distintas y hasta opuestas, sobre la vida y la muerte, sobre el sentido de la existencia» (59).

\section{TEORÍA DE LA LECTURA}

Las teorías de crítica literaria, como ya hemos visto, son respuesta del ser humano a las preguntas que un lector se hace ante un texto. Aunque todo crítico no es, en realidad, más que un lector, el cambio que instaló en el centro del análisis crítico al lector se ha conocido como crítica de la lectura, o crítica de la recepción. La crítica de la lectura surge, así, como una revolución de ésas que, como dice Suleiman (1980), «occur quietly: no manifestos, no marching and singing, no tumult in the streets; simply a shift of perspective, a new way of seeing what has always been there» (3). Pero las consecuencias de esta revolución han sido mayores que algunas de las grandes revoluciones políticas de la historia. Con la introducción de la crítica de la lectura surge toda una nueva perspectiva de la literatura y del fenómeno de la comunicación.

Desde el punto de vista de la crítica retórica de la lectura, es posible analizar las diferentes interpretaciones de la obra de Sábato. Los postulados teóricos de Booth ${ }^{10}$ sobre autor-implícito y lector-implícito permiten identificar las dos entidades involucradas en el proceso de comunicación. Sin embargo, debe rechazarse la concepción de Booth de este lectorimplícito como una entidad puntual y discreta, y más bien concebir a este lector-implícito como una variable, determinada por su situación histórica y social, y por todos los elementos que, en la concepción de Fish (1980), definen lo que propone como una «comunidad interpretativa». El ideal de este análisis es mantenerse en una postura abierta a diferentes «desconstrucciones» del texto y arribar a diferentes lecturas del mismo, para no caer en la limitación de la hermenéutica negativista, que postula una interpretación válida, y dejar abiertas las posibilidades en la línea de la hermenéutica múltiplo, donde el texto es más que la suma de todas las posibles lecturas.

El lector-implícito del que nos habla Booth puede manifestarse de

10 Wayne Booth, The Rethoric of Fiction (Chicago: University of Chicago Press, 1961). 
diferentes maneras en el texto. En esta línea de pensamiento, encuentro fructífera la distinción propuesta por Brooke-Rose (1980) en cuanto a la codificación del texto, ya que es determinante en la relación que se establece entre el narrador y el lector. Brooke-Rose habla de un «código superdeterminado» (an overdetermined code), de un «código indeterminado» (an undetermined code) y de un «código no-determinado» (a nondetermined code); y propone la necesidad de todo texto de establecer un balance: "The text overdetermines certain codes, but must compensate either by underdeterminig others, or by over- and underdetermining within the same code but in such a way that the final result is underdetermined» (147). De esta manera es posible estudiar, en forma discreta, la presencia del lector en el texto y establecer las relaciones que emergen del mismo en el proceso de la lectura.

\section{La lectura de los textos de Sábato}

La lectura de los textos de Sábato es una lectura conflictiva y vital; sus discursos inciden en los aspectos más sensibles del ser y conmueven al lector. No hay manera de permanecer indiferente ante unos textos en los que se increpa directamente al lector, en los que se le insulta y se le interpela con arrogancia, donde se encuentra un lector-implícito supercodificado en el texto, incluido como elemento estructural de la narración.

Una característica general del discurso sabatiano es ese narrador agresivo y vital. La misma actitud narrativa que encontramos en Juan Pablo Castel y Fernando Vidal Olmos la encontramos en el Sábato del ensayo y la polémica. Narradores obcecados por una idea fija, defensores acérrimos de una verdad incontestable, armados de una retórica agresiva. E1 lector de estos textos por fuerza debe reaccionar, debe entrar a formar parte de esa dinámica que, en un marco semiótico, define el acto de la lectura. Como dice Iser (1980): «As the reader passes through the various perspectives offered by the text, and relates the different views and patterns to one another, he sets the work in motion, and so sets himself in motion, too» (106).

\section{LA LECTURA EN «EL TÚNEL»}

La lectura como actividad social y proceso semiótico está presente desde la primera página de El túnel (de aquí en adelante ET). «Bastará 
decir que soy Juan Pablo Castel, el pintor que mató a María Iribarne; supongo que el proceso está en el recuerdo de todos y que no se necesitan mayores explicaciones sobre mi persona» (11). Este primer paradigma se desconstruye como «suponer una sociedad donde se leen periódicos, preferiblemente la sección de asesinatos, sobre todo cuando se trata de un pintor famoso». Más adelante es del todo explícito cuando nos dice que «... esa gente que siempre anda detrás de las explicaciones es la más curiosa, y pienso que ninguno de ellos se perderá la oportunidad de leer la historia de un crimen hasta el final» (14).

Juan Pablo Castel confiesa que escribió sus páginas porque «pensé que podrían ser leídas por mucha gente, ya que ahora soy célebre; y aunque no me hago muchas ilusiones acerca de la humanidad en general y de los lectores de estas páginas en particular, me anima la débil esperanza de que alguna persona llegue a entenderme. AunOUE SEA UNA SOLA PERSONA» (14). El mensaje que emerge del texto es complejo y ambivalente, formado por dos movimientos: uno de rechazo y otro de acercamiento al lector. La primera impresión viene causada por una agresividad dirigida directamente a la audiencia, «de quien no me hago muchas ilusiones», seguida de un gesto de humildad en «la esperanza de que alguna persona llegue a entenderme». Un mensaje que se desdobla en dos campos fenomenológicos, dos modos empáticos de establecer la comunicación. El lector vacila en su forma de reaccionar ante un signo que, a la vez que lo denigra, lo valora. Cómo entender la ambivalencia de este discurso, cómo situarse frente a él. He aquí una de las tantas disyuntivas que el texto nos ofrece, y es el lector el que debe desconstruir el código, aprehenderlo y responder ante él.

La conciencia de Castel sobre el acto de la lectura es evidente. La madrugada del asesinato, después de haberse entregado en la comisaría, Castel ve amanecer y dice: «Pensé que muchos hombres y mujeres comenzarían a despertarse y luego tomarían el desayuno y leerían el diario...» (135). Es evidente que en el mundo de Castel, de Fernando Sábato, la lectura es parte integral del proceso social. Leer es, por lo tanto, un fenómeno tan cotidiano como hablar o escuchar música; es parte de ser hombres y vivir en sociedad. La lectura, y sobre todo la lectura de las crónicas policiales de los diarios, tiene una importancia fundamental en el discurso sabatiano, ya que éste sirve como código semiótico en el desarrollo de la representación lineal del discurso.

Como dejamos estipulado al inicio de estas líneas, leemos para entender, nos acercamos a un texto con la esperanza de comprender, y al comprenderlo, entenderlo. Ahora bien, ser entendido por otro es una condición fundamental para entendernos a nosotros mismos, así como 
entender a otro es una dimensión de ese hecho de entenderse a sí mismo. En el fondo, Castel escribe sus páginas para llegar a entenderse a sí mismo, escribir y releer lo escrito, así como ser leído por otro, es una forma de trascender ese túnel «oscuro y solitario». Como dice Robert Crosman (1980): «The physical acts of pushing my pencil over the paper, and of casting my eye over the markings thus made, may be called by different names, but in practice they are inseparable. The very act of writing includes reading» (163).

La violencia de Castel hacia su lector, ejemplificada anteriormente, se reitera varias veces a lo largo de la lectura. Recuérdese el caso en que, llevado por su raciocinio lógico, Castel confiesa: «Observo que se está complicando el problema, pero no veo la forma de simplificarlo. Por otra parte, el que quiera dejar de leer esta narración en este punto no tiene más que hacerlo; de una vez por todas le hago saber que cuenta con mi permiso más absoluto» (18). Este narrador que encontramos en $E T$ es un narrador dispuesto a agredir, en cualquier momento, a su lector, al mismo tiempo que apela a las esferas más profundas y sensibles de su ser.

Para una idea más precisa del alcance que cobra la relación del sujeto-lector en $E T$, debe concretarse la importancia que el fenómeno de la lectura en sí tiene en el proceso semiótico de descodificación. Desde su primera instancia, ET articula su campo referencial en base a una serie de pretextos, pertenecientes al mundo periodístico y policial, erigiendo así su universo narrativo sobre lecturas previas y discursos precedentes. Por otro lado, ET es una exploración en el proceso de lectura, ya que todas las instancias de la fábula se relacionan con la lectura de textos: lectura del cuadro «Maternidad», lectura de conversaciones telefónicas, de cartas y notas, lectura de gestos y enunciados cinéticos, y por último, la lectura de la crónica de Castel, ET. En este sentido, $E T$ es la historia de la lectura de $E T$.

En este artículo me ocupo del fenómeno de la lectura en la obra de Sábato y, por lo tanto, no entro a discutir las implicaciones semióticas del análisis de los códigos, cosa que hago en otro artículo de próxima aparición. Quiero dejar asentado, no obstante, que estas aserciones se corroboran con la identificación de un código básico derivado de la crónica policial, como elemento generador del discurso de ET. La lectura de la crónica policial a la que alude Castel en el primer enunciado de $E T$, encierra en sí un punto clave del sistema semiótico de la obra de Sábato. 


\section{LA LECTURA EN «SOBRE HÉROES Y TUMBAS》}

Similar a la postura de Juan Pablo Castel en ET es la de Fernando Vidal Olmos en el "Informe sobre ciegos» (de aquí en adelante "Informe»). El punto de vista de ambos es semejante y comparten esa agresividad narrativa que también define al Sábato narrador de los ensayos. La capacidad polémica de Fernando se despliega, en toda su magnitud, en la conversación con Norma Pugliese e Inés González Iturrat en el café de la calle Paso (cap. XI). Ahí se puede ver al polemista sarcástico y agresivo, al hombre lúcido que discute con una furia y una lógica endemoniada. Fernando expone aquí su opinión sobre la lectura, para escándalo de la señora González Iturrat, que defiende la educación y las escuelas. Arguye Fernando en contra de los beneficios de la lectura que la «... Alemania de 1933 era uno de los pueblos más alfabetizados del mundo. Si la gente no supiera leer, al menos no podría ser idiotizada día a día por los diarios y revistas» (333).

El lector del «Informe» no puede menos que sentirse intimidado ante un interlocutor como Fernando. Al igual que lo que pasa con los seres que lo rodean en la ficción, tal como lo confiesa Bruno, el lector también se siente «dominado por aquel hombre ante quien era imposible permanecer indiferente. No era esa clase de seres que se pueden ver pasar a nuestro lado con indiferencia: instantáneamente nos atraía o nos repelía, y por lo general de dos modos a la vez» (464). El lector, codificado al fin y al cabo en un mismo texto, junto con Fernando, es víctima de su influjo. En el «Informe», también el lector está presente desde el principio, desde que se encuentra con ese signo interrogativo que encierra la totalidad del «Informe»: «¿Cuándo empezó esto que ahora va a terminar con mi asesinato?» (289). Esta pregunta es «referencial», en los términos de Todorov (1980: 68-69), ya que provee información sobre un hecho: la muerte de Fernando; y establece en forma general, abstracta, la totalidad de ese universo, el universo en que el lector está a punto de sumergirse. El enunciado de Fernando parece ser una pregunta retórica, pero es, a la vez, una interpelación directa al lector; es un grito de auxilio desesperado y violento. Su función es poner en movimiento la memoria del lector, que, al igual que la de Fernando, deberá empezar a proyectar su «intensísimo haz hacia vastas regiones de mi memoria» (289).

El lector del «Informe» no se queda, sin embargo, en este nivel del texto, sino que debe internarse en las profundidades del metatexto. Esto sucede cuando Fernando desarrolla su teoría sobre el caso Castel (XXV). 
Esta incursión de Fernando en el material de $E T$ nos lleva a otro nivel constructivo del texto; pasamos de la ficción a la metaficción, del personaje que piensa y recuerda a otro personaje de ficción. El referente de estos signos es, a su vez, signo de otro discurso precedente. Narrador y lector inician, así, una revisión del caso: « $Y$ volví entonces a analizar el caso Castel, caso que no sólo fue muy notorio por la gente implicada, sino por la crónica que desde el manicomio hizo llegar el asesino a una editorial» (396). El narrador se distancia del lector en cuanto a su relación con el caso, ya que «había conocido a María Iribarne y sabía que su marido era ciego» (396). El lector, en este momento, reconoce que su marco referencial es más restringido que el de Fernando; es decir, se encuentra ante un código indeterminado. El discurso del narrador juega constantemente con el campo afectivo del lector, cuando inmediatamente después dice: «Es fácil imaginar el interés que tuve de conocer a Castel, pero también es fácil presumir el temor que me impidió hacerlo, pues equivalía a meterse en la boca del lobo» (396). De haberlo deseado, Fernando podría haber conocido personalmente a Castel, cosa del todo imposible para el lector, lo que resulta en una constante variación de niveles miméticos. E1 individuo que personalmente conoció a María Iribarne y que tuvo la posibilidad de conocer a Castel, termina diciéndonos: «¿Qué otro recurso me quedaba que el de leer, el de estudiar minuciosamente su crónica?» (396). Estudiar minuciosamente su crónica es. exactamente lo que el lector ha hecho. De esta manera, Fernando introduce una ficción en su ficción y se mueve en varios niveles miméticos que, como ha demostrado Frye (1957: 33), se plantean en relación directa con el lector.

En el «Informe», la participación activa del lector en la construcción de la obra es evidente. En repetidas ocasiones el lector es llamado a reconstruir pasajes; tómese como ejemplo la instancia cuando, encerrado en el laberinto de la Secta, Fernando recuerda la historia del portero y la mucama que murieron de hambre encerrados en el ascensor (XXIV). El narrador presenta todo el marco referencial y aporta completos todos. los elementos proairéticos. Está en el proceso de imaginar los últimos recuerdos y suspiros de la pareja, cuando llama al lector a la acción: «Bueno, en fin, ¿para qué seguir con la descripción minuciosa? Cualquiera puede reconstruirla a poco que tenga alguna imaginación: Hambre creciente, sospechas mutuas, peleas, recriminaciones por cosas pasadas» (392). El sadismo de Fernando se regodea en la escatología y la antropofagia, e insiste en que el lector se deje llevar por ese camino: «No debe olvidar, el que quiera reconstruir este episodio, que, además, esos dos seres humanos deben hacer allí sus necesidades...» (393). Fer- 
nando, consciente del proceso de lectura que el texto incita, llama al lector a la reconstrucción de los significantes que se encuentran codificados en su texto, sarcásticamente nos da la opción de construir, de 1lenar los espacios vacíos, los blancos del texto, o continuar la lectura de la estructura stuperficial del mismo.

La relación dinámica entre narrador y lector se plantea siempre a un nivel consciente, es decir, por medio de una supercodificación del texto. El narrador tiene conciencia de narrar y, lo más importante, de ser leído, de estar siendo escuchado. De esta manera, su relación con el lector es abierta y dinámica y se sitúa al mismo nivel comunicativo. Considérese, por ejemplo, el siguiente enunciado: «Se me ocurre - dice Fernando- que al leer la historia de Norma Pugliese algunos de ustedes pensarán que soy un canalla» (340). Como puede verse, estamos en contacto con un lector que tiene plena conciencia de las diferentes comprensiones y construcciones del texto. Su violencia y arrogancia se desarrolla en las siguientes frases, donde acepta y justifica ser un canalla, sin ningún respeto para sí mismo, con un argumento que intimida directamente al lector: "¿y quién que ahonde en los pliegues de su conciencia puede respetarse?» (idem). Así, el lector, hombre que sin duda pretende ahondar en los pliegues de su conciencia, hombre que sin duda cree tener cierto respeto para sí mismo, se encuentra ante una irresoluble contradicción.

Fernando hace un recuento del caso Castel, dejando por sentado el hecho de que se trata de una venganza de la Secta, y propone una serie de variaciones o posibilidades. Concluye diciendo que: «Hay todavía algunas variantes de las variantes, que no vale la pena que yo describa, pues cada uno de ustedes puede fácilmente ensayar como ejercicio; ejercicio, por otra parte, útil, pues nunca se sabe cuándo y cómo puede caerse en alguno de los ambiguos mecanismos de la Secta» (398). Aquí el narrador introduce al lector activamente no sólo en la lectura, sino en la producción del texto; el lector es llamado a producir variantes y posibilidades, que son, a su vez, posibilidades del texto. Más aún, el narrador nos advierte sobre los peligros de la Secta e indirectamente amenaza al lector, "pues nunca se sabe cuándo ni cómo puede caerse». Llegamos, así, a este tercer nivel de la lectura, donde el lector pasa a situarse como protagonista del texto, porque nosotros también podemos ser víctimas de «los ambiguos mecanismos de la Secta».

Las últimas líneas del «Informe» no hacen más que confirmarnos esta advertencia de Fernando, comunicarnos claramente que también el lector, en el transcurso de la lectura, ha caído. Concluye Fernando diciendo: «Aquí termino, pues, mi Informe, que guardo en un lugar en 
que la Secta no pueda hallarlo» (440). Y, sin embargo, aquí estamos nosotros, con el «Informe» en la mano, leyendo la historia y asumiendo que la Secta no sólo lo halló, sino que decidió publicarlo, que decidió darlo a la luz en una novela que, sin lugar a dudas, escribió alguien por encargo de la Secta, o quizá hasta uno de sus miembros, para despistar a los ilusos lectores que se pensarán que todo es una ficción, que todo es la obra de un «insensato».

Al igual que como sucede con el discurso de $E T$, el «Informe» y en general todo $S H T$ es una complicada red de textos y lecturas, donde la nota periodística surge una vez más como modelo retórico, como código fundamental para la infinita reproducción del texto.

\section{LA LECTURA EN «ABADDÓN EL EXTERMINADOR»}

En $A E E$, el fenómeno de la lectura es todavía más compleja, ya que en esta obra la escritura es acción y motivo de un proceso de lectura y recreación. $A E E$ es escritura de un texto que presupone la lectura de textos precedentes. E1 lector de $A E E$ se mueve en un mundo compuesto de varios pretextos, un discurso que contiene una serie de discursos precedentes. De manera análoga al pretexto presente en $E T, A E E$ contiene en sus estructuras subyacentes los discursos que desde 1945 componen la escritura sabatiana. Esto es evidente en la afirmación de Sábato cuando en un café se encuentra con Nacho y experimenta «ese triste sentimiento que sólo los escritores pueden sufrir y que únicamente ellos pueden comprender, pensaba con amargura. Porque no basta ser conocido (como un actor o un político) para experimentar ese matiz de desazón: es imprescindible ser autor de ficciones, alguien que es enjuiciado no sólo por lo que son juzgadas las personas públicas, sino por lo que los personajes de novela son y sugieren» (58).

Los personajes de Sábato se mezclan en un mundo de lectura y textos. Bruno, por ejemplo, encuentra a Castel en $A E E$ en la unidad titulada «Un desconocido». Este discurso es un desdoblamiento magistral del fenómeno de la lectura e íntimamente ligado a la teoría de la «crónica policial». Bruno ve a Castel en un bar frente a una copa, pero no lo reconoce. «Ese hombre, pensó Bruno, está absoluta y definitivamente solo. No sabía por qué le resultaba conocido, y durante mucho tiempo rebuscó en su memoria, trató de vincularlo a alguna fotografía en diarios o revistas» (167). Hasta este momento el lector tampoco sabe de quién se está hablando; la única pista que se tiene relaciona al individuo con el periodismo. «Por otra parte, parecía asombroso que 
un individuo con ropa tan raída, un ser que llegado hasta ese último escalón, pudiera ser personaje de periodismo. A menos, se le ocurrió de pronto, que alguna vez haya tenido algo que ver con un hecho policial» (idem). En este momento el lector se instala de nuevo en el mundo de la «crónica policial», un terreno bastante familiar, y posiblemente empieza a recorrer los casos policiales que forman parte de su competencia intertextual. Cuando el desconocido sale, el narrador hace la siguiente observación: «Bruno, acostumbrado a escudriñar hombres en soledad, contemplativo y abúlico como era, pensó: "O es un criminal o es un artista"» (168). La duda continúa en Bruno por meses, "hasta que un día creyó recordar algo, tuvo una sospecha. Buscó en su archivo, archivo que no era ni el de un filósofo ni el de un escritor o periodista, sino más bien el archivo de un hombre para quien la humanidad constituye un doloroso misterio. Sí, ahí estaba la fotografía: el desconocido era aquel Juan Pablo Castel que en 1947 había matado a su amante» (168). En este momento el lector ideal de $A E E$, que tiene en su enciclopedia el discurso de 1948 y que recuerda a Castel, llevará a cabo ahora un proceso de inferencia para actualizar su lectura. Es interesante notar que el recorte que Bruno encuentra en su archivo es el pretexto de $E T$, es el enunciado que da lugar al discurso de ET. En este momento el acápite «Un desconocido» se revela en todo su sentido irónico, ya que el sujeto de la enunciación es «un conocido».

$A E E$ refuerza la hipótesis sobre la función cognocitiva de la «crónica policial». En $A E E$, Sábato camina por la calle Uruguay, «... toma un café en El Foro, compra La Razón y lee con cuidado las noticias, empezando desde atrás, ya que, según ha comprobado a lo largo de su vida, los diarios y revistas están hechos al revés, y las cosas más interesantes están siempre en las últimas páginas» (132). Es evidente que Sábato se refiere a la «crónica policial» y los acontecimientos criminales. La fuerza e importancia de la «crónica policial», así como su función sémica en el desarrollo de todo el discurso sabatiano, puede documentarse con una cita de la carta a un «querido y remoto muchacho», cuando discutiendo el tratamiento de un tema en el arte, dice: «Son los hombres los que son pequeños, grandes, sublimes o triviales. La «misma» historia del estudiante pobre que mata a una usurera puede ser una mera crónica policial o Crimen y castigo» (116). Similar a ésta es la referencia a Flaubert: «Y no vayas a creer que Flaubert escribió la historia de aquella pobre diabla porque se lo pidieron: escribió porque tuvo la súbita impresión de que en aquella historia policial podía escribir su propia y secreta historia policial, ridiculizándose a sí mismo con la misma crueldad con que sólo un gran neurótico puede hablar 
de su yo» (120). La importancia de la «crónica policial» como código generador del discurso es, como podemos ver, tanto una unidad semiótica —en su calidad de código - como una unidad temática —en su calidad ontológica.

La tematización de la lectura en $A E E$ se muestra a todo lo largo de sus páginas. El personaje Sábato se las pasa haciendo planes de escribir y leer, y para disculparse por no asistir a algunos eventos, alega un ataque de gota «... que por otra parte se produce apenas invocado. Ataque que le dura quince o veinte dias y que es aprovechado para leer de una buena vez El Quijote, prometiéndose que apenas salga del dolor se pondrá a escribir» (136). Las alusiones a la lectura son abundantes en $A E E$; proliferan las discusiones sobre lo que se lee y cómo se lee, sobre los beneficios y los maleficios de la lectura, sobre lo que se debería leer y cómo se debería leer. En definitiva, $A E E$ es una obra acerca de la influencia de la lectura en la vida de los seres humanos, los efectos que tiene la lectura en el hombre, y demuestra la enorme porción de nosotros mismos que es material semiótico.

Dice Suleiman (1980) que en el análisis del proceso de lectura hay dos cosas fundamentales: «the nature of the relationship between a text and an individual realization of it... and the status of the reading subject» (23). El objetivo de estas páginas ha sido relacionar estos dos aspectos, cuya importancia y trascendencia es fundamental en la evaluación de cualquier texto, con el interés de demostrar que la estructura del discurso sabatiano tiene intima relación con el concepto de lectura y escritura que subyace en el mismo.

\section{SignifiCACIÓN DE LA LECTURA}

En $E E F$ leemos: «Una de las misiones de la gran literatura: despertar al hombre que viaja hacia el patíbulo» (27). La lectura, por tanto, medio a través del cual accedemos a la literatura, tiene como función primordial el despertar, el echar a andar la máquina de la conciencia, el activar un proceso de reescritura y recreación del mundo que aspira de alguna manera a significar al ser humano.

La forma en que leemos tiene fundamental importancia en diferentes aspectos de la crítica literaria: influye en la discusión sobre géneros literarios, ya que entre género literario y lectura existe una relación mutua y dinámica perfilada por la competencia del sujeto lector. La forma en que leemos una tira cómica, una novela de Dostoyevski o un manual de álgebra está condicionada por una tradición, por un conjunto de 
valores y símbolos, por el significado que el signo «tira cómica», «novela» o «álgebra» despierta en el sistema semiótico del lector, por los diferentes valores que cada uno de esos signos representa para la determinada comunidad de lectores a la cual el lector pertenece. Como dice Culler ${ }^{11}$ : «Reading and interpretation may be carried out in solitude, but they are highly social activities, which cannot be separated from the interpersonal and institutional conventions that are explicitly manifested in literary journals, critical discussions, and literary education» (52).

Leer es, por lo tanto, una forma de comportamiento social, una forma de asegurarnos una posición en una sociedad bibliocrática, una forma de acceder al conocimiento y al poder. La relación que se establece entre el narrador de estos textos y el lector implícito en ellos determina de manera radical el resultado del acto de lectura. La significación que se desprende de la desconstrucción de sus enunciados está inevitablemente permeada por esa relación ambigua y dinámica: ese rechazo violento que nos provoca y esa atracción ineludible que nos seduce al reconocernos en el texto con todas nuestras angustias y nuestras ansiedades, desnudos signos lectores de otro signo, de otra representación concreta en las que sospechamos algún significado, algún valor, al igual que lo sospechamos en nosotros mismos.

11 Christine Brooke-Rose, «The Readerhood of Man», en The Reader in the Text, Suleiman \& Crosman, eds. (Princeton: Princeton University Press, 1980), páginas $120-148$. 